American J. of Engineering and Applied Sciences 2 (4): 665-668, 2009

ISSN 1941-7020

(C) 2009 Science Publications

\title{
Microstructure Affecting Cutting Quality in Fine Blanking Process
}

\author{
Bopit Bubphachot \\ Faculty of Engineering, Mahasarakham University, Mahasarakham, Thailand
}

\begin{abstract}
Problem statement: Fine blanking process is a high precision process and worldwide in developed countries. Since specimen does not occur fracture on the cutting edge and it is not necessary to decorate again in the finishing process for the fine blanking which can be reduced some operation steps. For example, if chain wheel of motorcycle is produced by conventional blanking, it needs nine steps. But, if it is produced by fine blanking, it requires only three steps. With these reasons, fine blanking is boom for the metal forming industry in Thailand. But, due to some mechanical properties for some kinds of metal such as low elongation or imperfect microstructure, it is not cut by using fine blanking directly. Approach: Objective of this research was to investigate microstructure of specimen for fine blanking process in order to avoid fracture surface on blank. The optimum condition will result in higher elongation while having small decrease in tensile strength. The circular specimen with diameter of $16 \mathrm{~mm}$ and thickness of $2 \mathrm{~mm}$ was chosen. Material was steel which contains $0.45 \%$ carbon. Results: Microstructures contained pearlite and ferrite grains. The grains sizes were expanded with temperature of heat treatments at 700,800 and $900^{\circ} \mathrm{C}$, respectively, for $1 \mathrm{~h}$. The specimen exposes to heat treatment in each temperature results in the increase of overall shear surface and the decrease of fracture surface when compared with no heat treatment. This is due to no appearance of strain hardening. For the microstructures exposed to heat treatment at $700^{\circ} \mathrm{C}$ for $10-20 \mathrm{~h}$ were almost spherroidite. It revealed that facture surface became shear surface after heat treatment over $10 \mathrm{~h}$. Conclusion/Recommendations: The changes of microstructure for $0.45 \%$ carbon steel significantly affected to the overall shear and fracture surface and yield strength due to increasing of spherroidite, thus fracture was decreased with time.
\end{abstract}

Key words: Fine blanking, fracture surface, heat treatment, pearlite, spherroidite

\section{INTRODUCTION}

Fine blanking process is a high precision process and worldwide in developed countries. Since specimen does not occur fracture on the cutting edge, it is usually occurred fracture for conventional blanking as shown in Fig. 1. Thus, it is not necessary to decorate again in the finishing process for the fine blanking which can be reduced some operation steps. For example, if chain wheel of motorcycle is produced by conventional blanking, it needs nine steps. But, if it is produced by fine blanking, it requires only three steps ${ }^{[1,3]}$. With these reasons, fine blanking is boom for the metal forming industry in Thailand.

Due to some mechanical properties for some kinds of metal such as low elongation or imperfect microstructure, it is not cut by using fine blanking directly. The fractureon cutting edgeis still occurred, although punch and die mold are perfectly designed ${ }^{[4-7]}$.

Several researches emphasize on a specific variable or a condition of fine blanking e.g., effect of distance between $\mathrm{V}$-ring ${ }^{[1-3]}$. A few researches study the improvement of property of material for fine blanking.

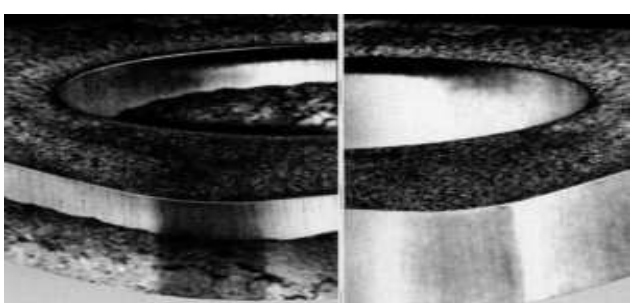

(a)

(b)

Fig. 1: Specimens of different processes

(a) conventional blanking (b) fine blanking

Birzer $^{[1]}$ proposed that microstructure and mechanical property of carbon steel which was able to cut by fine blanking but detail of microstructure of specimen for converting to the proper structure that ready for cutting is not clear. This research is to investigate the effect of microstructure in fine blanking process without fracture surface. The temperature and time of heat treatment are varied for studying the trend of decreasing of fracture surface after cutting by using fine blanking process. In addition, the microstructure of specimen after exposure to heat treatment is also analyzed. 


\section{MATERIALS AND METHODS}

Specimen preparation: perimentThe exal material is $0.45 \%$ carbon steel with thickness of $2 \mathrm{~mm}$. A specimen is prepared in $50 \times 50 \mathrm{~mm}$ square shape by fine blanking and another prepare for testing tension with size according to JIS: Z 2201 No.13 B.

Punch and die design: Material that used for making a mold follows tool steel (JIS: SKD 11) standard and treat the hardness to the level of 64HRC \pm 2 . Distance between punch and die is fixed at $0.5 \%$ of thickness of specimen. Distance between V-ring and V-ring height are 1.4 and $0.4 \mathrm{~mm}$, respectively. Lubricant ISOLUBE 4686 is used during cutting. The design method of Vring $^{[1]}$ is shown in Fig. 2.

Heat treatment process: Heat treatment processes are totally seven different conditions as follow:

- Test specimens are annealed at the temperature of 700,800 and $900^{\circ} \mathrm{C}$ for $1 \mathrm{~h}$ and then cooled down in the normal atmosphere

- Test specimens are annealed at the temperature of $700^{\circ} \mathrm{C}$ for $5,10,15$ and $20 \mathrm{~h}$ and then cooled down in the normal atmosphere

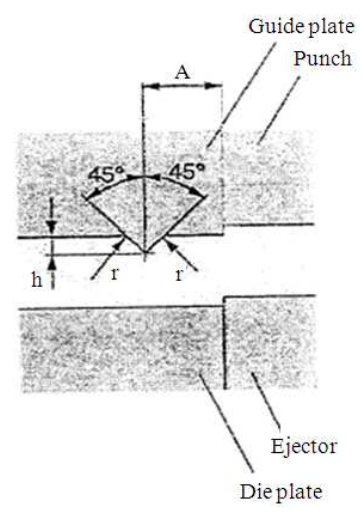

\begin{tabular}{|c|c|c|c|}
\hline $\begin{array}{c}\text { Material } \\
\text { thickness } \\
(\mathrm{mm})\end{array}$ & $\begin{array}{c}\mathrm{A} \\
(\mathrm{mm})\end{array}$ & $\begin{array}{c}\mathrm{H} \\
(\mathrm{mm})\end{array}$ & $\begin{array}{c}\mathrm{R} \\
(\mathrm{mm})\end{array}$ \\
\hline $1.0-1.7$ & 1.0 & 0.3 & 0.2 \\
\hline $1.8-2.2$ & 1.4 & 0.4 & 0.2 \\
\hline $2.3-2.7$ & 1.7 & 0.5 & 0.2 \\
\hline $2.8-3.2$ & 2.1 & 0.6 & 0.2 \\
\hline $3.3-3.7$ & 2.5 & 0.7 & 0.2 \\
\hline $3.8-4.5$ & 2.8 & 0.8 & 0.2 \\
\hline
\end{tabular}

Fig. 2: Parameter of v-ring design

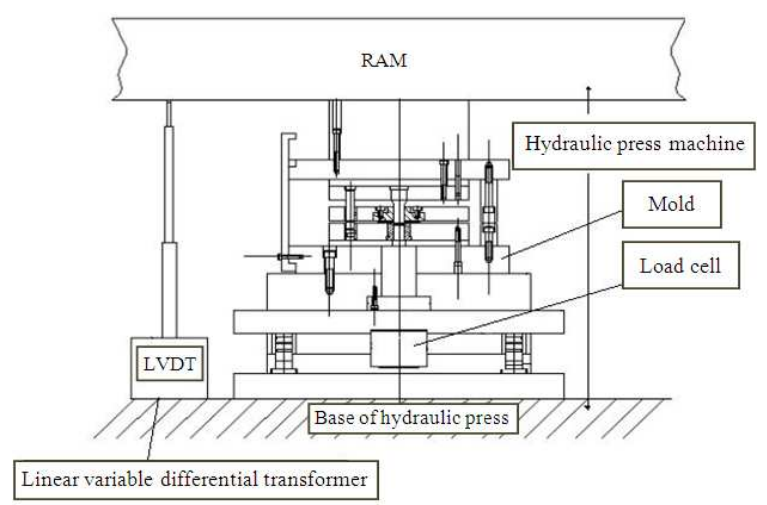

Fig. 3: Experimental setup
The hydraulic press is single action in size of 150 tones. The nitrogen gas spring is used for supporting force on V-ring. The displacement data is transmitted through load cell and Linear Variable Differential Transformer (LVDT) and then is converted to force and displacement distance by DASY lab software. The experimental setup is shown in Fig. 3.

\section{RESULTS}

Effect of temperature: The microstructures are occurred pearlite and ferrite grains. The grains sizes are expanded with the temperature of heat treatments at 700, 800 and $900^{\circ} \mathrm{C}$ as shown in Fig. $4 \mathrm{a}-\mathrm{c}$, respectively.

For relationship between cutting surface and burr with heat treatment temperature is shown in Fig. 5.

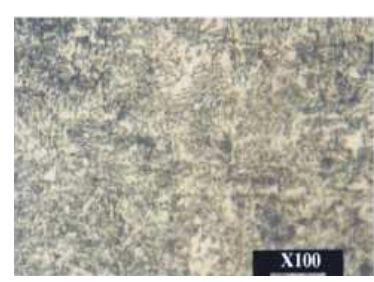

(a)

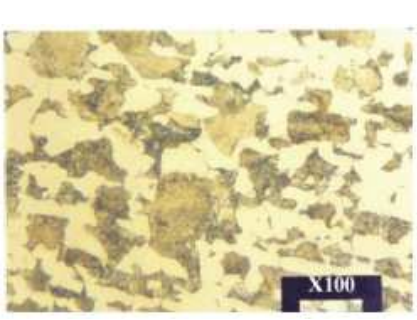

(c)

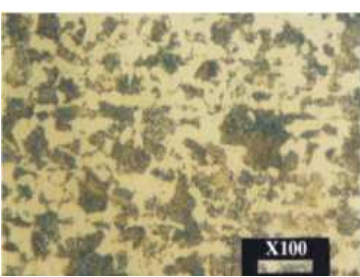

(b)
Fig. 4: Annealed microstructure of specimens at different temperatures. (a) $700^{\circ} \mathrm{C}$ (b) $800^{\circ} \mathrm{C} \mathrm{(c)}$ $900^{\circ} \mathrm{C}$

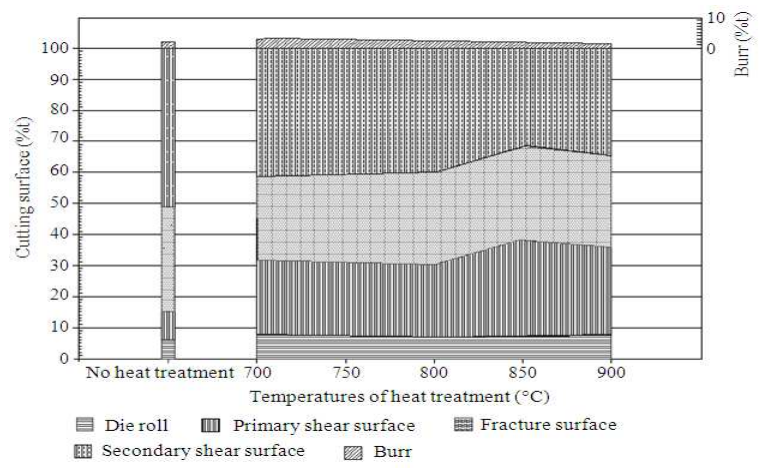

Fig. 5: Cutting edge of specimen at different temperatures 


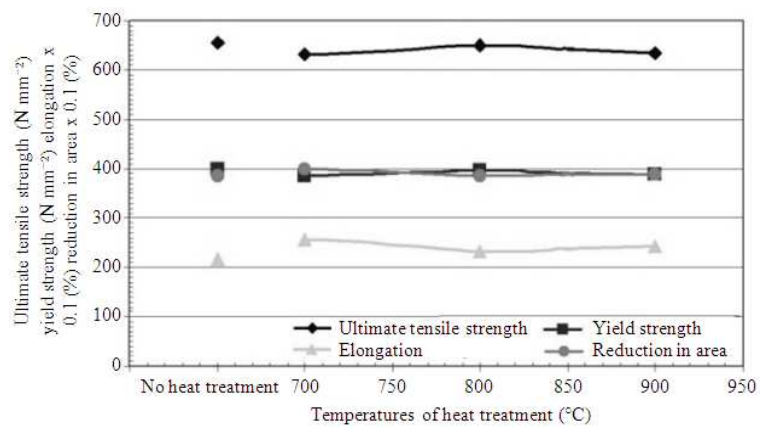

Fig. 6: Tensile strength of annealed specimens at different temperatures

From experimental result, it shows that specimens expose to heat treatment at each temperature results in the increase of overall shear surface and the decrease of fracture surface when compared with no heat treatment due to no appearance of strain hardening.

The mechanical properties such as ultimate tensile strength and elongation are plotted with temperature of heat treatment as shown in Fig. 6. The results of specimen after heat treatment, the elongation are increased while ultimate tensile and yield strengths decreased. At the temperature of $700^{\circ} \mathrm{C}$, the elongation is the highest value but ultimate tensile and yield strengths are the lowest values. For the other temperatures, elongation, ultimate tensile and yield strengths are almost the same results.

Effect of time: The microstructures are exposed to heat treatment at $700^{\circ} \mathrm{C}$ for $10-20 \mathrm{~h}$ are almost spherroidite as seen in Fig. 7b-d, respectively. On the other hand, microstructures for the first $10 \mathrm{~h}$ are significantly remained pearlite inside structure as shown in Fig. 7a.

Figure 8 is a graph of the cutting surface and burr against time for heat treatment. It reveals that the overall shear surface after heat treatment in the first $10 \mathrm{~h}$ is increased, while the fracture surface is decreased. When heat treatment is over $10 \mathrm{~h}$, the fracture surface disappears from the cutting surface.

Relationship of mechanical properties before and after heat treatment against annealing time is shown in Fig. 9. The elongation is exponential increased while ultimate tensile and yield strengths are exponential decreased. After $20 \mathrm{~h}$ of heat treatment, the increasing of elongation is approximately $59.7 \%$ but the reduction of ultimate tensile and yield strengths is about 27.43 and $25.27 \%$, respectively when compared with no heat treatment.

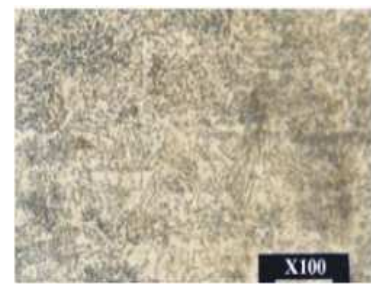

(a)

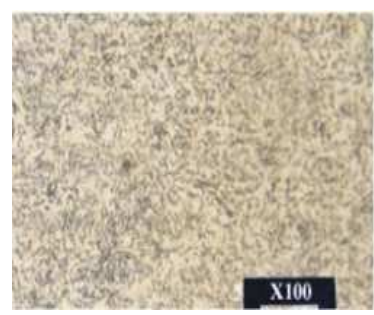

(c)

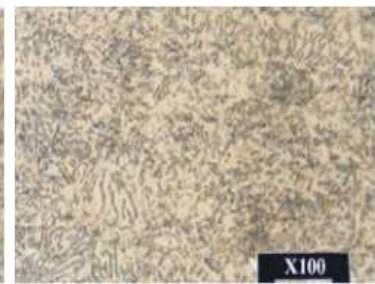

(b)

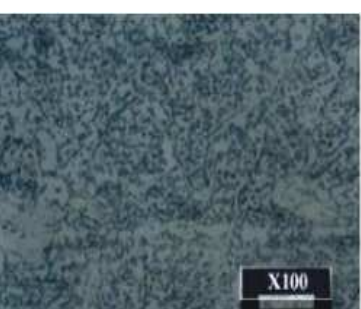

(d)
Fig. 7: Annealed microstructure of specimen at $700^{\circ} \mathrm{C}$ for different times. (a) $5 \mathrm{~h}$ (b) $10 \mathrm{~h} \mathrm{(c)} 15 \mathrm{~h} \mathrm{(d)}$ $20 \mathrm{~h}$

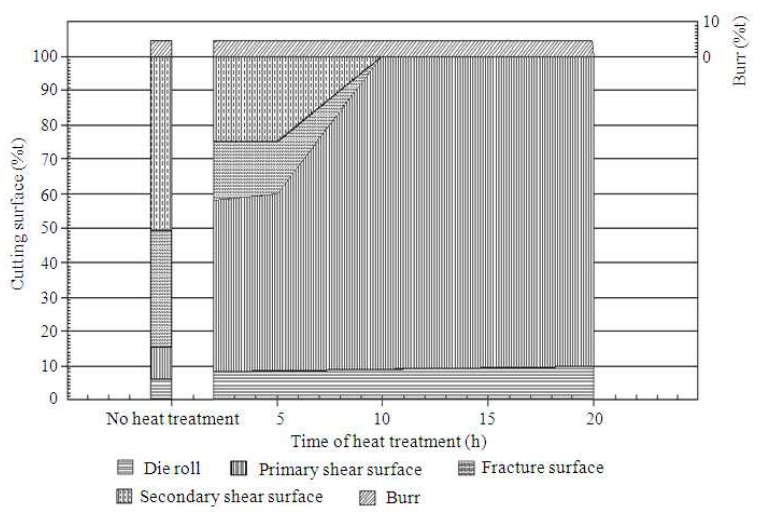

Fig. 8: Cutting edge of specimen at deferent times

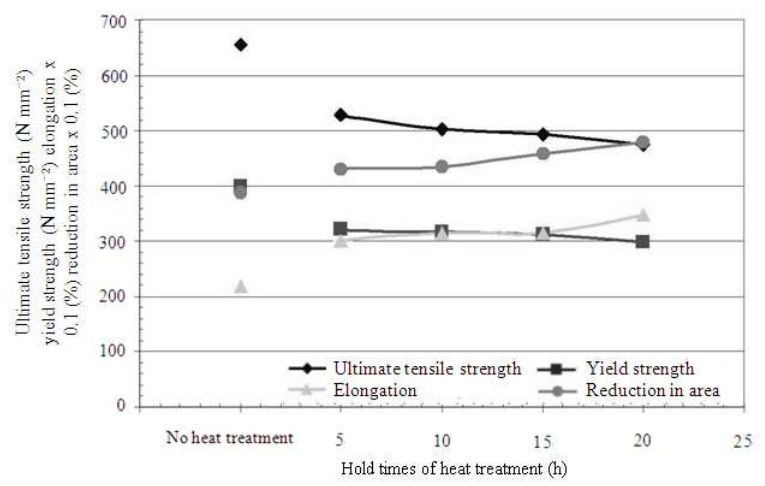

Fig. 9: Tensile strength of annealed specimens at different hold times 


\section{DISSCUSION}

Effect of microstructure on the cutting quality of $0.45 \%$ carbon steel in fine blanking process shows that the remained pearlite grain still results in the facture surface, although punch and die mold are perfectly designed. However, the width of fracture surface is decreased when the microstructure in pearlite changes to spherroidite grain. Also, there is no fracture surface when the perfect change from pearlite to spherroidite grain completely. Moreover, the mechanical properties of materials particularly elongation which has high value in spherroidite, result in the shear surface only ${ }^{[1-9]}$.

\section{CONCLUSION}

The changes of microstructure for $0.45 \%$ carbon steel significantly affect to the overall shear and fracture surface and yield strength due to increasing of spherroidite, thus the fracture is decreased with time.

\section{ACKNOWLEDGEMENT}

The researcher would like to express the appreciation to the Department of Tool and Materials Engineering, Faculty of Engineering, King Mongkut's University of Technology Thonburi, Bangkok Thailand for supporting data.

\section{REFERENCES}

1 Birzer, F., 1997. From Conventional Stamping to Fine Blanking. Forming and Fine Blanking. Feintool, Germany, ISBN: 3-478-93161-4, pp: 17-23.

2 Isamu, A. and Toshinori, T., 2003. Material Flow Analysis on Shearing Process by Applying Fourier Phase Correlation Method-analysis of Piercing and Fine-blanking. J. Mate. Process. Technol., 134: 45-52. DOI: 10.1016/S0924-0136(02)00917-2
3 Lange, K., 1985. Fine Blanking. Handbook of Metal Forming. McGraw-Hill, New York, ISBN: 0070362858, pp: 900.

4 Michigan Precision Industries, Fine Blanking Process.http://www.freepatentsonline.com/356495 9.html?query $=+$ Fine+Blanking\&stemming $=$ on

5 Sutasn, T., J. Masahiko, T. Kanaizuka, K. Yamamoto and M. Masao, 2008. Prediction of fineblanked surface characteristics using the Finite Element Methoa (FEM). J. Mater. Process. Technol., 198: 391-398. DOI: 10.1016/j.jmatprotec.2007.07.027

6 Sutasn, T., 2009. Finite element analysis of v-ring indenter mechanism in fine-blanking process. Mater. Des., 30: 526-531. DOI: 10.1016/j.matdes.2008.05.072

7 Chen, Z.H., C.Y. Tang, T.C. Lee and L.C. Chan, 1999. A study of strain localization in the fineblanking process using the large deformation finite element method. J. Mate. Process. Technol., 86: $163-167 . \quad$ DOI: $10.1016 /$ S09240136(98)00306-9

8. George, E.T. and A.H.H. Maurice, 1997. Steel Heat Treatment Handbook. New York, ISBN: 08247-9750-7.

9. Omar, B., K. Naser and A. Musa, 2008. The effect of shot peening and polishing on the pitting corrosion resistance of stainless steel. Am. J. Applied Sci., 5: 1397-1402. http://www.scipub.org/fulltext/ajas /ajas51013971402.pdf 